Abstracta Iranica Abstracta Iranica

Revue bibliographique pour le domaine irano-aryen

Volume 26 | 2005

Comptes rendus des publications de 2003

\title{
Aspects of Empire in Achaemenid Sardis. Cambridge, Cambridge University Press, 2003, 325 p., index, 103 fig.
}

\section{Rémy Boucharlat}

\section{(2) OpenEdition}

Journals

Édition électronique

URL : http://journals.openedition.org/abstractairanica/3288

DOI : 10.4000/abstractairanica.3288

ISSN : 1961-960X

Éditeur :

CNRS (UMR 7528 Mondes iraniens et indiens), Éditions de l'IFRI

\section{Édition imprimée}

Date de publication : 15 mai 2005

ISSN : 0240-8910

Référence électronique

Rémy Boucharlat, "Aspects of Empire in Achaemenid Sardis. Cambridge, Cambridge University Press, 2003, 325 p., index, 103 fig. », Abstracta Iranica [En ligne], Volume 26 | 2005, document 94, mis en ligne le 08 décembre 2005, consulté le 25 septembre 2020. URL : http://journals.openedition.org/ abstractairanica/3288; DOI : https://doi.org/10.4000/abstractairanica.3288

Ce document a été généré automatiquement le 25 septembre 2020

Tous droits réservés 


\title{
Aspects of Empire in Achaemenid Sardis. Cambridge, Cambridge University Press, 2003, 325 p., index, 103 fig.
}

\author{
Rémy Boucharlat
}

1 Sardes, capitale du royaume lydien en Asie Mineure, devint celle de la satrapie de Lydie après la conquête de Cyrus. Son rôle politique et économique avant et après la conquête d'une part, l'importance des fouilles et recherches dont elle a fait l'objet depuis 1958 d'autre part, permettent de construire la monographie que propose l'A. Celle-ci rappelle cependant que la période achéménide a été relativement peu explorée par rapport à la ville lydienne antérieure, plus spectaculaire par son architecture, ses tombes et son matériel, et que seule une fraction de la cité a été explorée. Cette situation, banale en archéologie, ne fait pas moins de Sardes un témoin de première importance de la vie d'un lieu dans l'empire achéménide. Ajoutons que les sources écrites, passages des auteurs anciens et près de cinquante inscriptions, souvent brèves et incomplètes, complètent la diversité des sources d'information.

2 La thèse déclarée de l'A. est celle d'un impact profond de l'empire perse sur une élite pluriethnique qui absorba les traditions iraniennes, grecques et locales; de même que l'ensemble de la population reçut et adopta bien des aspects de cette nouvelle culture que l'A. qualifie de "sardienne ", en ce sens qu'elle présente des caractéristiques qui lui sont propres pour certaines, parfois sont partagées par l'ensemble de l'Anatolie, mais ne sont guère comparables à celles que l'on trouverait dans d'autres parties de l'empire qui fut divers.

3 Cette monographie propose (chap. 2) un survol des évènements à partir des auteurs grecs essentiellement, bien que quelques tablettes inscrites des Fortifications de Persépolis mentionnent Sardes et des personnages de cette ville ou de la région. Le chap. 3 est une présentation de la ville, urbanisme, monuments et habitats, qui informent sur la répartition des classes sociales et des lieux de pouvoir et de culte - 
mais le fameux paradeisos, le parc, reste introuvable. La sculpture d'époque achéménide (chap. 4) reflète la diversité culturelle des commanditaires que traduisent dans la pierre les artisans locaux. La majorité des inscriptions (chap. 5) sont en lydien et continuent les traditions antérieures; deux sont cependant bilingues lydiennesaraméennes, deux autres lydiennes-grecques, dont la fameuse inscription de Droaphernès qui documente certaines pratiques religieuses. Les pratiques funéraires sont elles aussi d'abord traditionnelles, mais des éléments extérieurs y apparaissent, dont le plus spectaculaire est illustré par 'la tombe pyramidale' qui serait largement inspirée de la tombe de Cyrus à Pasargades.

Le chapitre 8, consacré aux sceaux, traite avant tout un seul cylindre trouvé à Sardes ; trente quatre sceaux, dont la moitié sont pyramidaux, ont été trouvés dans les fouilles anciennes; ils montrent la même diversité de styles que les sceaux et empreintes de Persépolis. Même si beaucoup se rapportent au style "gréco-perse " que certains préfèrent appeler aujourd'hui anatolien achéménide, ce qui est tout aussi conjectural selon l'A., car trop précis au plan géographique, historique et culturel. La céramique, enfin, marque une nette influence iranienne par l'abondance des 'Achaemenid bowls', des vases carénés, au profil arrondi qui dérivent des modèles de l'âge du Fer iranien et sont traduits à l'époque achéménide dans la vaisselle de métal. La tradition restera forte, puisque trois des huit dépôts de tels bols sont datés du $3^{\mathrm{e}} \mathrm{s}$. av. J.-C.

Sardes est un cas d'étude que l'A. a su rendre de première importance, malgré les grandes lacunes de la documentation. On aimerait que d'autres cités de l'empire achéménide fassent l'obj et de la même tentative de monographie, mais il n'est pas sûr que beaucoup offrent les mêmes possibilités.

INDEX

Thèmes : 3.2.2. Pré-Achéménides et Achéménides

\section{AUTEURS}

RÉMY BOUCHARLAT

CNRS - Lyon 